\title{
Analisis Tingkat Kepuasan Konsumen Berdasarkan Kualitas Pelayanan pada Pengunjung Objek Wisata Pantai Pulau Merah Kabupaten Banyuwangi
}

\section{(Analysis Of Customer Satisfaction On Quality Of Service In Tourism Beach Red Island Visitor District Banyuwangi )}

\author{
Mohamad Jajang I, Diah Yulisetiarini, Hadi $\mathrm{P}^{1}$ \\ Jurusan Manajemen, Fakultas Ekonomi dan Bisnis, Universitas Jember (UNEJ) \\ Jln. Kalimantan 37, Jember 68121 \\ E-mail: lumajajang@gmail.com
}

\begin{abstract}
Abstrak
Artikel ini bertujuan untuk menganalisis tingkat kepuasan konsumen terhadap kualitas layanan yang meliputi bukti fisik, kehandalan, daya tanggap, jaminan, dan empati pada objek wisata Pantai Pulau Merah. Populasi dalam penelitian ini adalah pengunjung Pantai Pulau Merah. Metode sampling yang digunakan adalah non-probability sampling yaitu Purposive Sampling dengan jumlah responden sebanyak 108 orang. Variabel yang digunakan yaitu Kualitas Pelayanan. Alat analisis yang digunakan adalah SERVQUAL dan diuji dengan Uji Wilcoxon Signed Rank Test. Hasil penelitian menunjukan bahwa 1) Bukti fisik memiliki delapan indikator yang mana semua indikator menunjukan kepuasan pengunjung pantai Pulau Merah. 2) Kehandalan memiliki dua indikator yang mana keduanya menunjukan kepuasan pengunjung pantai Pulau Merah. 3) Daya tanggap memiliki dua indikator yang mana keduanya menunjukan kepuasan pengunjung pantai Pulau Merah. 4) Jaminan memiliki dua indikator yang mana keduanya menunjukan kepuasan pengunjung pantai Pulau Merah. 5) Empati memiliki lima indikator yang mana kelimanya menunjukan kepuasan pengunjung pantai Pulau Merah.
\end{abstract}

Kata Kunci: Kepuasan Konsumen, Kualitas Pelayanan, Servqual, Wilcoxon Signed Rank Test.

\section{Abstract}

Thisarticle aim to anayze the level of satisfaction of customer on the quality of services that includes physical evidence, dependability, responsiveness, assurance, and empathy on subjects tourist Red Island Beach. The population in this research was visitors of The Red Island Beach. Sampling method used was non-probability sampling namely purposive sampling with the number of respondents as much as 108 people. Variables used the quality of services. The analysis methode uses Service Quality (SERVQUAL).The results demonstrates that 1) physical evidence has eight indicator which all indicators showed satisfaction visitors of Red Island Beach.2) dependability indicator having two roomates they showed satisfaction visitors of Red Island Beach. 3) responsiveness indicator having two roomates they showed satisfaction visitors of Red Island Beach. 4) assurance indicator having two roomates they showed satisfaction visitors of Red Island Beach .5) empathy have five indicator roomates showed satisfaction reviews those five visitors of coastal islands red.

Keyword: Consumer Satisfaction, Quality of Service, Servqual, Wilcoxon Signed Rank Test.

\section{Pendahuluan}

Indonesia merupakan negara yang kaya akan potensi Sumber Daya Alam (SDA) yang melimpah. Sumber Daya Alam di Indonesia terbagi menjadi dua kategori, yaitu SDA Hayati dan SDA Nonhayati. SDA Hayati meliputi tumbuhan, pertanian, perkebunan, peternakan dan perikanan. Sedangkan SDA Nonhayati meliputi air, angin, sinar matahari, dan hasil tambang. Tingginya tingkat SDA Hayati yang dimiliki oleh Indonesia, menjadikan Indonesia sebagai negara dengan tingkat biodeversitas tertinggi kedua di dunia setelah Brazil. Kepariwisataan merupakan salah satu bidang yang erat kaitanya dengan pemanfaatan SDA Hayati yang ada di Indonesia. Dengan memiliki lebih dari 17.100 pulau, 1,9 juta $\mathrm{km}^{2}$ luas daratan, 3,1 juta $\mathrm{km}^{2}$ luas perairan, lebih dari 300 ragam suku dan etnis, serta warisan sejarah di hampir masing-masing wilayahnya, Indonesia merupakan negara yang memiliki potensi Pariwisata yang besar. Diperkirakan saat ini Indonesia memiliki sebanyak 962 destinasi wisata (destinasiwisata.id). pemerintah Indonesia selaku pengambil kebijakan dibidang pariwisata saat ini menjalankan progam Visit Indonesia. Salah satu daerah di Indonesia yang memiliki perkembangan industri pariwisata yang baik adalah Kabupaten Banyuwangi.

Kabupaten Banyuwangi merupakan salah satu kabupaten yang ada di Jawa Timur, Indonesia. Kabupaten ini merupakan Kabupaten yang berada di ujung paling timur pulau Jawa yang juga merupakan kabupaten terluas di Jawa Timur sekaligus di Pulau Jawa, luas wilayahnya mencapai 5.782,50 $\mathrm{km}^{2}$. Selain itu Kabupaten Banyuwangi memiliki slogan pariwisata "sunrise van java", yang memiliki maksud tempat terbitnya mentari pagi pertama di Pulau Jawa. Kabupaten Banyuwangi mempunyai Objek Daya Tarik Wisata (ODTW) yang sangat beragam. Terdapat objek wisata berupa pantai/laut, pegunungan, hutan/taman nasional dan lainya.

Tabel 1. Kunjungan Wisatawan Tahun 2009-2013 Kabupaten Banyuwangi

\begin{tabular}{lccccc}
\hline \multicolumn{1}{c}{ Indikator } & $\mathbf{2 0 0 9}$ & $\mathbf{2 0 1 0}$ & $\mathbf{2 0 1 1}$ & $\mathbf{2 0 1 2}$ & $\mathbf{2 0 1 3}$ \\
\hline $\begin{array}{l}\text { Kunjungan } \\
\text { wisatawan } \\
\text { domestik } \\
\text { (orang) }\end{array}$ & 398.210 & 649.681 & 401.968 & 1.312 .092 & 1.554 .500 \\
& & & & &
\end{tabular}

1 Corresponding Author 


\begin{tabular}{llllll}
\hline $\begin{array}{l}\text { Kunjungan } \\
\text { wisatawan } \\
\text { mancanegara } \\
\text { (orang) }\end{array}$ & 11.392 & 16.890 & 42.938 & 50.783 & 60.706 \\
\hline
\end{tabular}

Sumber: RKPD Banyuwangi 2015

Tingkat kunjungan wisatawan baik domestik maupun mancanegara ke Banyuwangi relatif meningkat pesat dari tahun ke tahun, hal ini merupakan salah satu indikator kesuksesan pemerintah dalam bidang kepariwisataan. Dengan memiliki kekayaan SDA yang besar khususnya dalam bidang pariwisata, Banyuwangi memiliki potensi besar di sektor pariwisata (Eko, 2008:1). Dalam rangka menciptakan Banyuwangi sebagai tujuan wisata, pemerintah kabupaten Banyuwangi menerapkan strategi yang disebut segi tiga berlian "The Diamond Triangle". Salah satu objek wisata unggulan Banyuwangi yang juga termasuk dalam strategi the diamond triangle adalah Pantai Pulau Merah. Berada di Desa Sumberagung, Kecamatan Pesanggaran. Lokasi Pantai Pulau Merah berjarak sekitar $60 \mathrm{~km}$ dari pusat kota Banyuwangi. Perpaduan kejernihan air laut dengan pasir putih sejauh $3 \mathrm{~km}$ dan dibagian timur pantai terdapat barisan gunung serta pepohonanya terlihat kawasan wisata ini nampak subur. Pemkab Banyuwangi sendiri sudah bertekad menjadikan Pulau Merah sebagai destinasi untuk berselancar yang menjadi salah satu andalan wisata Banyuwangi.

Data menunjukan pada tahun 2014 kunjungan ke Pantai Pulau Merah sekitar 200.000 pengunjung, sedangkan pada tahun 2015 mencapai 276.000 pengunjung (banyuwangikab.go.id). Seiring dengan peningkatan jumlah pengunjung pengelolaan beberapa kualitas layanan yang ada di Pulau Merah juga terus diperbaiki dan diperbaharui.

Semua itu dilakukan agar mendapat kepuasan konsumen, apabila layanan yang diterima oleh konsumen lebih baik atau sama dengan apa yang konsumen bayangkan, maka konsumen cenderung akan mencoba kembali (Oka, 2000:45). Semua hal yang berkaitan dengan pariwisata serta layanan jasa wisata tersebut ditujukan untuk mampu memenuhi permintaan wisatawan akan kepuasan berpariwisata yang pada akhirnya pengelola mengharapkan mampu meningkatkan jumlah wisatawan yang berkunjung di patai Pulau Merah baik wisatwan domestik maupun mancanegara.

Evaluasi mengenai kepuasan atau ketidakpuasan terhadap layanan yang sudah diberikan serta mengetahui kesenjangan (gap) antara harapan dengan kinerja yang dirasakan pengunjung objek wisata pantai Pulau Merah sangat penting. Tingkat kualitas layanan tidak dapat dinilai berdasarkan sudut pandang perusahaan melainkan harus dilihat dari sudut pandang penilaian konsumen (Rangkuti, 2006:18). Parasuraman et al. (1985), mengidentifikasi sepuluh dimensi pokok kualitas jasa, yaitu reliabilitas, responsifitas, akses, kesopanan, komunikasi, kredibilitas, keamanan, kemampuan memahami pelanggan, dan bukti fisik. Namun setelah melalui beberapa riset selanjutnya Parasuraman, Zeithaml dan Berry menemukan overlapping diantara beberapa dimensi di atas. Parasuraman, Zeithaml dan Berry menyederhanakan sepuluh dimensi tersebut menjadi lima dimensi pokok yaitu, Kompetensi, Kesopanan, Kredibilitas, dan keamanan disatukan menjadi jaminan (Assurance). Sedangkan akses, komunikasi, dan kemampuan memahami pelanggan diintegrasikan menjadi empati (Emphaty). Dengan demikian terdapat lima dimensi utama yang disusun sesuai urutan tingkat kepentingan relatifitasnya sebagai berikut:

\section{1) Bukti fisik (Tangibles)}

Merupakan penampilan fasilitas fisik perlengkapan seperti bangunan gerai, tempat parkir, kebersihan, kerapihan dan kenyamanan ruangan, serta penampilan karyawan.

2) Kehandalan (Reliability)

Reliability merupakan kemampuan untuk memberikan layanan yang sesuai dengan yang dijanjikan dengan segera, akurat dan memuaskan. Terdapat dua aspek dalam dimensi ini, yaitu kemampuan perusahaan untuk memberikan layanan seperti yang dijanjikan, dan seberapa jauh suatu perusahaan mampu memberikan layanan akurat atau tidak ada error.

3) Daya tanggap (Responsiveness)

Responsiveness merupakan kesigapan karyawan dalam membantu konsumen dan memberikan layanan yang cepat dan tanggap, yang meliputi : kesigapan karyawan dalam melayani pelanggan, kecepatan karyawan dalam menangani transaksi, dan penanganan keluhan pelanggan.

\section{4) Jaminan (Assurance)}

Assurance meliputi kualitas keramahtamahan karyawan, perhatian dan kesopanan dalam memberi layanan, sifat dapat dipercaya yang dimiliki para staf dan karyawan, serta ketrampilan dalam memberikan informasi.

\section{5) Empati (Emphaty)}

Perhatian secara individual yang diberikan kepada perusahaan, dalam hal ini pemilik usaha ritel kepada pelanggan untuk memahami keinginan dan kebutuhan pelanggannya dan kemampuan karyawan untuk berkomunikasi dengan pelanggan. Dimensi emphaty sendiri meliputi:

a) komunikasi, merupakan kemampuan komunikasi untuk menyampaikan informasi kepada pelanggan atau pun memperoleh masukan dari pelanggan.

b) pemahaman kepada pelanggan (understanding the customer), meliputi usaha perusahaan untuk mengetahui dan memahami kebutuhan serta keinginan konsumen.

Berdasarkan teori dan bukti empiris maka dapat disimpulkan hipotesis yaitu Ekspektasi kualitas pelayanan lebih besar dari persepsi kualitas pelayanan pantai Pulau Merah.

\section{Metode Penelitian}

\section{Rancangan atau Desain Penelitian}

Jenis penelitian dalam penulisan ini adalah penelitian deskriptif analitis yaitu salah satu metode yang menggambarkan variabel demi variabel dengan tujuan untuk mengumpulkan informasi dan gejala secara rinci dan mengidentifikasikan masalah dan memeriksa kondisi dan praktik-praktik yang berlaku.

\section{Jenis dan Metode Pengumpulan Data}

Jenis data yang digunakan dalam penelitian ini termasuk jenis data kualitatif yang diolah dan dianalisis menggunakan metode SERVQUAL. Bila dilihat dari sumber datanya, maka 
pengumpulan data dapat menggunakan sumber data primer dan sekunder. Sumber data primer dari penelitian ini diperoleh langsung dari responden penelitian dengan cara membagikan kuesioner di lapangan. Sumber data sekunder dari penelitian ini diperoleh dari dinas terkait, yaitu pemerintah Kabupaten Banyuwangi dan Dinas Pariwisata Banyuwangi. Teknik pengumpulan data dalam penelitian ini dengan cara membagikan kuesioner kepada wisatawan Pantai Pulau Merah Banyuwangi.

\section{Populasi dan Sampel}

Populasi dari penelitian ini adalah pengunjung pantai Pulau Merah kabupaten Banyuwangi. Teknik pengambilan sampel pada penelitian ini menggunakan accidental sampling, yaitu teknik penentuan sampel berdasarkan kebetulan. Maksudnya adalah siapa saja yang kebetulan bertemu dengan peneliti dapat digunakan sebagai sampel, bila dipandang orang tersebut sesuai kriteria dan cocok untuk dijadikan sumber data (Sugiyono, 2011).Sampel pada penelitian ini adalah pengunjung Pantai Pulau Merah yang dapat diminta informasi secara jelas oleh peneliti. Sampel yang dipakai dalam artikel ini adalah 108 orang dengan menggunakan teori Ferdinand (2006:48)

\section{Metode Analisis Data}

Metode analisis data yang digunakan dalam artikel ini adalah tehnik SERVQUAL. Adapun instrumen SERVQUAL dijadikan dalam satu tabel pernyataan, dimana setiap pernyataan terdapat dua jawaban yaitu tingkat ekspektasi dan tingkat persepsi. Kolom ekspektasi untuk mengukur tingkat harapan penerima layanan dan kolom persepsi untuk mengukur persepsi layanan yang diterima. Jumlah pernyataan adalah 18 pernyataan dan mencakup tentang lima dimensi kualitas layanan. Selanjutnya untuk menghitung perbedaan ekspektasi dengan persepsi digunakan rumus kepuasan konsumen, dengan rumus sebagai berikut (Parasuraman et al, 1985):

Dimana :

$$
\mathrm{Q}=\mathrm{P}-\mathrm{E}
$$

$\mathrm{Q}=$ Quality / Kualitas layanan

$\mathrm{E}=$ Expectation / Harapan konsumen atas kualitas layanan

$\mathrm{P}=$ Perceived / Layanan yang sesungguhnya diterima

Berdasarkan hasil perhitungan tersebut dapat diketahui bagaimana tingkat kesenjangan (gap) yang terjadi. Setelah itu dilakukan Uji Hipotesis Wilcoxon Signed Rank Test untuk data berpasangan. Data berpasangan dalam penelitian ini yaitu ekspektasi dan persepsi yang diisi oleh responden.

\section{Hasil Penelitian}

\section{Data Penelitian}

Berikut statistik deskriptif rekap jawaban responden pada lima varibel ekspektasi kualitas pelayanan pantai Pulau Merah. Tabel 2 menunjukan bahwa responden rata-rata memiliki ekspektasi pelayanan dimensi bukti fisik yang tinggi atau diatas angka 4, hal ini berarti sebagian besar responden memeiliki harapan yang tinggi terhadap pelayanan dimensi bukti fisik yang ada di pantai Pulau Merah. Responden rata-rata memiliki ekspektasi pelayanan dimensi kehandalan yang sedang yang ditunjukan pada angka 4 , hal ini berarti sebagian besar responden memeiliki harapan yang sedang terhadap pelayanan dimensi kehandalan yang ada di pantai Pulau Merah. Responden rata-rata memiliki ekspektasi pelayanan dimensi daya tanggap yang tinggi atau diatas angka 4, hal ini berarti sebagian besar responden memeiliki harapan yang tinggi terhadap pelayanan dimensi daya tanggap yang ada di pantai Pulau Merah. Responden rata-rata memiliki ekspektasi pelayanan dimensi jaminan yang tinggi atau diatas angka 4, hal ini berarti sebagian besar responden memeiliki harapan yang tinggi terhadap pelayanan dimensi jaminan yang ada di pantai Pulau Merah. Responden rata-rata memiliki ekspektasi pelayanan dimensi empati yang sedang yang ditunjukan pada angka 4 , hal ini berarti sebagian besar responden memiliki harapan yang sedang terhadap pelayanan dimensi empati yang ada di pantai Pulau Merah.

Tabel 2. Penilaian responden terhadap ekspektasi kualitas pelayanan

\begin{tabular}{lccccccccc}
\hline Variabel & \multicolumn{6}{c}{ Rata-rata Jawaban Responden (\%) } & \multirow{2}{*}{ Total } \\
\cline { 2 - 7 } & 1 & 2 & 3 & 4 & 5 & 6 & 7 & \\
\hline Bukti Fisik & 0.3 & 1.3 & 2.9 & 6.9 & 17.3 & 38.8 & 32.1 & 100 \\
Kehandalan & 1.4 & 3.2 & 12.9 & 30.5 & 27.3 & 16.2 & 8.3 & 100 \\
$\begin{array}{l}\text { Daya } \\
\text { Tanggap }\end{array}$ & 0 & 0 & 1.9 & 13.4 & 18.1 & 35.2 & 31.5 & 100 \\
Jaminan & 0 & 0.9 & 1.8 & 11.5 & 18.5 & 36.7 & 31.3 & 100 \\
Empati & 1.4 & 4.1 & 10.4 & 27.5 & 21.9 & 19.4 & 15.1 & 100 \\
\hline
\end{tabular}

Tabel 3. Penilaian responden terhadap persepsi kualitas pelayanan

\begin{tabular}{lccccccccc}
\hline \multirow{2}{*}{ Variabel } & \multicolumn{6}{c}{ Rata-rata Jawaban Responden (\%) } & \multirow{2}{*}{ Total } \\
\cline { 2 - 7 } & 1 & 2 & 3 & 4 & 5 & 6 & 7 & \\
\hline Bukti Fisik & 3.4 & 8.7 & 11.5 & 20.8 & 23.5 & 20.6 & 11.6 & 100 \\
Kehandalan & 1.4 & 3.2 & 12.9 & 30.5 & 27.3 & 16.2 & 8.3 & 100 \\
$\begin{array}{l}\text { Daya } \\
\text { Tanggap }\end{array}$ & 0.4 & 2.4 & 13.9 & 26.9 & 24 & 18.5 & 13.8 & 100 \\
Jaminan & 0 & 0.9 & 1.8 & 11.5 & 18.5 & 35.6 & 31.3 & 100 \\
Empati & 0.9 & 5 & 8.3 & 27.3 & 24.1 & 21.3 & 12.9 & 100 \\
\hline
\end{tabular}

Tabel 3 menunjukkan bahwa responden rata-rata memiliki persepsi pelayanan dimensi bukti fisik yang tinggi atau diatas angka 4, hal ini berarti sebagian besar responden memiliki penilaian persepsi yang tinggi terhadap pelayanan dimensi bukti fisik yang ada di pantai Pulau Merah. Responden ratarata memiliki persepsi pelayanan dimensi kehandalan yang sedang yang ditunjukan pada angka 4 , hal ini berarti sebagian besar responden memeiliki penilaian kenyataan yang sedang terhadap pelayanan dimensi kehandalan yang ada di pantai Pulau Merah. Responden rata-rata memiliki persepsi 
pelayanan dimensi daya tanggap yang sedang yang ditunjukan pada angka 4, hal ini berarti sebagian besar responden memeiliki penilaian kenyataan yang sedang terhadap pelayanan dimensi daya tanggap yang ada di pantai Pulau Merah. Responden rata-rata memiliki persepsi pelayanan dimensi jaminan yang tinggi atau diatas angka 4 , hal ini berarti sebagian besar responden memeiliki penilaian kenyataan yang tinggi terhadap pelayanan dimensi jaminan yang ada di pantai Pulau Merah. . Responden rata-rata memiliki persepsi pelayanan dimensi empati yang sedang yang ditunjukan pada angka 4, hal ini berarti sebagian besar responden memiliki penilaian kenyataan yang sedang terhadap pelayanan dimensi empati yang ada di pantai Pulau Merah.

Tabel 4. Hail Uji Hipotesis Ekspektasi dengan Persepsi Kualitas Pelayanan

\begin{tabular}{|c|c|c|c|c|}
\hline Dimensi & Indikator & $\mathrm{z}_{\text {score }}$ & $\mathrm{z}_{\text {table }}$ & Keterangan \\
\hline \multirow[t]{8}{*}{ Bukti Fisik } & 1 & $-6,859$ & $-1,645$ & $\begin{array}{c}\mathrm{H}_{0} \\
\text { diterima }\end{array}$ \\
\hline & 2 & $-5,674$ & $-1,645$ & $\begin{array}{c}\mathrm{H}_{0} \\
\text { diterima }\end{array}$ \\
\hline & 3 & -6.163 & $-1,645$ & $\begin{array}{c}\mathrm{H}_{0} \\
\text { diterima }\end{array}$ \\
\hline & 4 & -5.507 & $-1,645$ & $\begin{array}{c}\mathrm{H}_{0} \\
\text { diterima }\end{array}$ \\
\hline & 5 & -3.755 & $-1,645$ & $\begin{array}{c}\mathrm{H}_{0} \\
\text { diterima }\end{array}$ \\
\hline & 6 & -6.717 & $-1,645$ & $\begin{array}{c}\mathrm{H}_{0} \\
\text { diterima }\end{array}$ \\
\hline & 7 & -7.466 & $-1,645$ & $\begin{array}{c}\mathrm{H}_{0} \\
\text { diterima }\end{array}$ \\
\hline & 8 & -6.479 & $-1,645$ & $\begin{array}{c}\mathrm{H}_{0} \\
\text { diterima }\end{array}$ \\
\hline \multirow[t]{2}{*}{ Kehandalan } & 9 & -6.019 & $-1,645$ & $\begin{array}{c}\mathrm{H}_{0} \\
\text { diterima }\end{array}$ \\
\hline & 10 & -5.607 & $-1,645$ & $\begin{array}{c}\mathrm{H}_{0} \\
\text { diterima }\end{array}$ \\
\hline
\end{tabular}

\begin{tabular}{lcccc}
\hline \multicolumn{1}{c}{ Dimensi } & Indikator & $\mathrm{z}_{\text {score }}$ & $\mathrm{z}_{\text {table }}$ & Keterangan \\
\hline $\begin{array}{l}\text { Daya } \\
\text { Tanggap }\end{array}$ & 11 & -6.246 & $-1,645$ & $\begin{array}{c}\mathrm{H}_{0} \\
\text { diterima }\end{array}$ \\
& 12 & -5.744 & $-1,645$ & $\begin{array}{c}\mathrm{H}_{0} \\
\text { diterima }\end{array}$ \\
Jaminan & 13 & -6.306 & $-1,645$ & $\begin{array}{c}\mathrm{H}_{0} \\
\text { diterima }\end{array}$
\end{tabular}

$\begin{array}{ccccc} & 14 & -5.315 & -1,645 & \begin{array}{c}\mathrm{H}_{0} \\ \text { diterima }\end{array} \\ \text { Empati } & 15 & -5.400 & -1,645 & \begin{array}{c}\mathrm{H}_{0} \\ \text { diterima }\end{array} \\ & 16 & -5.859 & -1,645 & \begin{array}{c}\mathrm{H}_{0} \\ \text { diterima }\end{array} \\ & 17 & -5.285 & -1,645 & \begin{array}{c}\mathrm{H}_{0} \\ \text { diterima }\end{array} \\ & & & & \\ & & & & \mathrm{H}_{0} \\ \text { diterima }\end{array}$

Uji hipotesis dalam artikel ini menggunakan uji Wilcoxon signed rank test. Uji Wilcoxon signed rank test digunakan untuk menguji perbedaan (gap) antar data berpasangan dengan level signifikasi yang digunakan 5\% atau 0,05 . Apabila z score lebih besar dari z Tabel maka dapat dikatan terdapat perbedaan (gap) antar ekspektasi dan persepsi. Nilai z Tabel untuk taraf signifikasi 0,05 adalah 1,645, tanda negatif (-) atau posiftif pada $\mathrm{z}$ Tabel menyesuaikan dengan angka $\mathrm{z}$ hitungnya (Singgih, :391).

Tabel 4 menunjukkan bahwa hasil uji pada semua indikator setiap dimensi kualitas pelayanan mendapatkan nilai $\mathrm{z}_{\text {score }}$ lebih kecil dari nilai nilai $z_{\text {tabel }}$ sehingga Ho diterima dan dapat dikatan bahwa ekspektasi kualitas pelayanan lebih kecil dari persepsi kualitas pelyanan. . Hal ini menunjukkan bahwa terjadi kepuasan pengunjung terhadap kualitas pelayanan dalam setiap indikator pelayanan di pantai Pulau Merah.

\section{Pembahasan}

\section{a. Dimensi bukti fisik}

Berdasarkan hasil penelitian pada artikel ini diketahui bahwa ekspektasi bukti fisik lebih kecil dari persepsi bukti fisik pada semua indikator. Hasil yang menunjukan lebih kecilnyua ekspektasi dibandingkan persepsi pengunjung dapat menggambarkan bahwa $\mathrm{H} 0$ diterima dan Ha ditolak, artinya pengunjung merasa puas terhadap pelayanan bukti fisik yang terdiri dari indikator tersedianya wahana permainan air, tersedianya gazebo pantai, tersedianya perahu yang nyaman, tersedianya papan selancar yang bagus, tersedianya tempat parkir yang luas, tersedianya musholah yang nyaman, tersedianya toilet umum yang bersih, dan kondisi lingkungan yang bersih.

\section{b. Dimensi Kehandalan}

Berdasarkan hasil penelitian pada artikel ini diketahui bahwa ekspektasi kehandalan lebih kecil dari persepsi kehandalan pada semua indikator. Hasil yang menunjukan lebih kecilnya ekspektasi dibandingkan persepsi pengunjung dapat menggambarkan bahwa $\mathrm{H} 0$ diterima dan Ha ditolak, artinya pengunjung merasa puas terhadap pelayanan kehandalan yang terdiri dari indikator tersedianya fasilitas yang sesuai dengan iklan, dan tersedianya layanan yang sesuai dengan iklan.

c. Dimensi Daya tangap 
Berdasarkan hasil penelitian pada artikel ini diketahui bahwa ekspektasi daya tanggap lebih kecil dari persepsi daya tanggap pada semua indikator. Hasil yang menunjukan lebih kecilnya ekspektasi dibandingkan persepsi pengunjung dapat menggambarkan bahwa $\mathrm{H} 0$ diterima dan Ha ditolak, artinya pengunjung merasa puas terhadap pelayanan daya tanggap yang terdiri dari indikator tersedianya petugas memberikan pelayanan dengan cepat, dan petugas selalu bisa diharapkan.

\section{d. Dimensi jaminan}

Berdasarkan hasil penelitian pada artikel ini diketahui bahwa ekspektasi jaminan lebih kecil dari persepsi jaminan pada semua indikator. Hasil yang menunjukan lebih kecilnya ekspektasi dibandingkan persepsi pengunjung dapat menggambarkan bahwa $\mathrm{H} 0$ diterima dan Ha ditolak, artinya pengunjung merasa puas terhadap pelayanan jaminan yang terdiri dari indikator penjaga pantai mampu memberikan rasa aman, petugas sopan santun dalam melayani pengunjung.

\section{e. Dimensi Empati}

Berdasarkan hasil penelitian pada penelitian ini diketahui bahwa ekspektasi jaminan lebih kecil dari persepsi jaminan pada semua indikator. Hasil yang menunjukan lebih kecilnya ekspektasi dibandingkan persepsi pengunjung dapat menggambarkan bahwa H0 diterima dan Ha ditolak, artinya pengunjung merasa puas terhadap pelayanan jaminan yang terdiri dari indikator pengelola objek wisata memberikan perhatian kepada pengunjung, petugas tersenyum saat melayani pengunjung, petugas berkomunikasi secara baik, petugas bekerja secara professional.

\section{Simpulan}

Berdasarkan analisis yang telah dilakukan pada penelitian ini, maka dapat ditarik kesimpulan sebagai berikut:

a. Bukti fisik memiliki delapan indikator yang mana semua indikator menunjukan kepuasan pengunjung pantai Pulau Merah, delapan indikator yang menunjukan kepuasan adalah tersedianya wahana permainan air, tersedianya gazebo pantai, tersedianya perahu yang nyaman, tersedianya papan selancar bagus, tersedianya musholah yang nyaman, tersedianya tempat parkir yang luas, tersedianya toilet umum yang bersih, dan kondisi lingkungan yang bersih. delapan indikator tersebut tidak memuaskan pengunjung karena tidak sesuai dengan ekspektasi pengunjung. Delapan indikator tersebut memuaskan pengunjung karena persepsi pengunjung sesuai atau lebih besar dari ekspektasi pengunjung.

b. Kehandalan memiliki dua indikator yang mana keduanya menunjukan kepuasan pengunjung pantai Pulau Merah. Dua indikator yang menunjukan kepuasan adalah tersedianya fasiitas yang sesuai dengan iklan, dan tersedianya layanan yang sesuai dengan iklan. Dua indikator tersebut memuaskan pengunjung karena persepsi pengunjung sesuai atau lebih besar dari ekspektasi pengunjung.

c. Daya tanggap memiliki dua indikator yang mana keduanya menunjukan kepuasan pengunjung pantai Pulau Merah. Dua indikator yang menunjukan kepuasan adalah petugas memberikan pelayanan dengan cepat, dan petugas selalu bisa diharapkan. Dua indikator tersebut memuaskan pengunjung karena persepsi pengunjung sesuai atau lebih besar dari ekspektasi pengunjung.

d. Jaminan memiliki dua indikator yang mana keduanya menunjukan kepuasan pengunjung pantai Pulau Merah. Dua indikator yang menunjukan kepuasan adalah penjaga pantai mampu memberikan rasa aman, dan petugas sopan santun dalam melayani pengunjung. Dua indikator tersebut memuaskan pengunjung karena persepsi pengunjung sesuai atau lebih besar dari ekspektasi pengunjung.

e. Empati memiliki lima indikator yang mana kelimanya menunjukan kepuasan pengunjung pantai Pulau Merah. Lima indikator yang menunjukan kepuasan adalah Pengelola objek wisata memberikan perhatian kepada pengunjung, Petugas tersenyum saat melayani pengunjung, Petugas berkomunikasi secara baik, Petugas bekerja secara profesional. Lima indikator tersebut memuaskan pengunjung karena persepsi pengunjung sesuai atau lebih besar dari ekspektasi pengunjung.

\section{Keterbatasan}

Bagi peneliti selanjutnya sebaiknya menggunakan metode ini pada objek di bidang lain sehingga hasil penelitian tidak memiliki keterbatasan dalam generalisasi.

\section{Ucapan Terima Kasih}

Terima kasih kepada pengelola wisata pantai Pulau Merah beserta pengunjung, dan Dinas Kebudayaan dan Pariwisata Kabupaten Banyuwangi sebagai responden yang telah meluangkan waktu untuk mengisi kuesioner dan memberikan informasi berkaitan dengan penelitian ini, sehingga penelitian ini dapat terselesaikan dengan baik.

\section{Daftar Pustaka}

Eko Wahyuni Rahayu. 2008. Barong Using : Aset Wisata Budaya Banyuwangi. Banyuwangi : Dinas Kebudayaan dan Pariwisata Kabupaten Banyuwangi

Ferdinand, Augusty, 2006. Metode Penelitian Manajemen. Semarang: Badan Penerbit Universitas Diponegoro

Oka A Yoeti. 2000. Ilmu Pariwisata. Jakarta : Pertaja.

Parasuraman, A., V.A. Zeithaml, and L.L Berry. 1985. A Conceptual model of service quality and its implications for future research. Jurnal of Service Research Vol.49 (85), No. 3, 213-233.

Rangkuti Fredy. 2006. Measuring Customer Satisfaction. Jakarta: Gramedia Pustaka Utama.

Singgih Santoso. 2015. SPSS 20 Pengolah Data Statistik di Era Informasi. Bandung: PT Elex Media Komputindo.

Sugiyono. 2002. Statistika Untuk Penelitian. Bandung: CV. Alfabeta.

www.banyuwangitourism.com

www.banyuwangikab.go.id

www.destinasiwisata.id 